\title{
Rapid Detection of Alternaria Species Involved in Pear Black Spot Using Loop-Mediated Isothermal Amplification
}

\author{
Xue Yang, ${ }^{1,2,3}$ Yong-Jie Qi, ${ }^{4,5}$ Mohamed N. Al-Attala, ${ }^{1,6}$ Zheng-Hui Gao, ${ }^{4,5}$ Xing-Kai Yi, ${ }^{4,5}$ Ai-Fang Zhang, ${ }^{1,2,3}$ \\ Hao-Yu Zang, ${ }^{1,2,3}$ Chun-Yan Gu, ${ }^{1,2,3}$ Tong-Chun Gao, ${ }^{1,2,3}$ and Yu Chen ${ }^{1,2,3, \dagger}$ \\ ${ }^{1}$ Institute of Plant Protection and Agro-products Safety, Anhui Academy of Agricultural Sciences, Hefei 230031, China \\ ${ }^{2}$ Scientific Observing and Experimental Station of Crop Pests in Hefei, Ministry of Agriculture, China \\ ${ }^{3}$ Laboratory of Quality \& Safety Risk Assessment for Agro-Products, Hefei, Ministry of Agriculture, China \\ ${ }^{4}$ Institute of Horticulture, Anhui Academy of Agricultural Sciences, Hefei 230031, China \\ ${ }^{5}$ Key Laboratory of Genetic Improvement and Ecophysiology of Horticultural Crop, Anhui Province, China \\ ${ }^{6}$ Plant Pathology Unit, Plant Protection Department, Desert Research Center, Cairo 11753, Egypt
}

\begin{abstract}
Alternaria species are the most important fungal pathogens that attack various crops as well as fruit trees such as pear and cause black spot disease. Here, a loop-mediated isothermal amplification (LAMP) assay is developed for the detection of Alternaria species. A. alternata cytochrome $\mathrm{b}(c y t-b)$ gene was used to design two pairs of primers and amplified a 229-bp segment of Aacyt-b gene. The results showed that LAMP assay is faster and simpler than polymerase chain reaction (PCR). LAMP assay is highly sensitive method for the detection of about $1 \mathrm{pg}$ of genomic DNA of A. alternata by using optimized concentration

DNA of 46 fungal species, only the tubes containing DNA of Alternaria spp. except A. porri, A. solani, and A. infectoria changed color from orange to yellowish green with SYBR Green I including the main pathogens of pear black spot. The yellowish green color was indicative of DNA amplification. Moreover, LAMP assay was used for testing infected tissues among 22 healthy and diseased pear tissues; the orange color changed to yellowish green for infected tissues only. Altogether, we conclude that $c y t-b$ gene can be used for the detection of Alternaria spp. via LAMP assay, which is involved in pear black spot disease.
\end{abstract} of $\mathrm{MgCl}_{2}(4 \mathrm{mM})$ in final LAMP reaction. In contrast, the limit of detection was $1 \mathrm{ng}$ of target DNA via conventional PCR. Among the genomic
Keywords: fungi, fruit, tree fruits, pathogen detection
The genus Alternaria is ubiquitous and includes both plant pathogenic and saprophytic species (Dang et al. 2015). Alternaria spp. may damage crops in the field or cause postharvest decay (Logrieco et al. 2003; Peever et al. 2004). This genus includes more than 280 species and causes at least $20 \%$ of crop damage (Gannibal 2015). Alternaria spp. are able to produce various secondary metabolites. Over 260 different metabolites have been reported to be produced by this genus. Several Alternaria metabolites known as potent mycotoxins (e.g., alternariol, alternariol methyl ether, altenuene, and tenuazonic acid) have an important role in pathogenesis on plants (Lou et al. 2013; Meena et al. 2017). Moreover, Alternaria spp. have

${ }^{\dagger}$ Corresponding author: Y. Chen; chenyu66891@sina.com

Xue Yang, Yong-Jie Qi, and Mohamed N. Al-Attala share joint first authorship for this work.

Funding: This research was supported by the National Key Research and Development Program of China (2018YFD0201400); National Natural Science Foundation of China (31672061 and 31872003); Project of Agro-Product Safety Monitoring from the Ministry of Agriculture, China; Natural Science foundation of Anhui Province (1808085QC91); the Anhui Provincial "115" Innovation Team; the Anhui Provincial Fruit Industrial System (AHCYTX14); and the program for construction of the Key Laboratory of Anhui Academy of Agricultural Sciences (18S1103 and 2019YL048). The Ministry of Science and Technology China provided financial support to M. N. AlAttala under the Talented Young Scientist Program.

The author(s) declare no conflict of interest.

Accepted for publication 17 June 2019.

(C) 2019 The American Phytopathological Society a wide host range, e.g., apple, blueberry, date palm, lemon, pear, potato, strawberry, tomato, and wheat (Al-Nadabi et al. 2018; He et al. 2018; Ito et al. 2004). Pear (Pyrus spp.) is one of the most common fruits and has a long history as an economic crop in commercial cultivation in more than 50 countries (Bao et al. 2008; Bassil and Postman 2010; Terakami et al. 2009; Wolko et al. 2010). More than 35 different disease causing agents (bacterial, fungal, viral, and nematodes) affect different parts of pear trees and represent a constraint on the pear industry worldwide (Zhang et al. 2011).

Pear black spot disease (PBS) can cause necrosis on pear leaves, twigs, and fruits. The symptoms first appear as small purple dots on the leaves of young shoots near to the ground. Then, dots grow to circular spots and become purplish black or brown. The same symptoms appear on the pear fruits but are black and slightly sunken (Tanahashi et al. 2016). Appropriate conditions such as high temperature and humidity make PBS disease more serious and severe (Reis et al. 2007). PBS is caused by several species of Alternaria such as A. alternata, A. gaisen, A. tenuissima, A. ventricosa, and $A$. yaliinficiens). Now, $A$. ventricosa and A. yaliinficiens have been isolated and identified from the export Ya Li Chinese pear in the United States (Roberts 2005, 2007). Until now, none of these species has been isolated from pear in China.

The routine technique for the detection and identification of Alternaria spp. often requires culture isolation, and morphological and physiological characterization (Simmons 2007). This process is tedious and time-consuming, whereby it takes several days to weeks to obtain a diagnostic result. Finding easier, highly sensitive and specific method is an important task for the detection and identification of plant pathogens in the primary stages or before their outbreak on plants. Currently, many different methods are available for this purpose, such as polymerase chain reaction (PCR), nested PCR, real-time PCR, helicase-dependent amplification (HDA), and recombinase polymerase amplification (RPA) (Lau and Botella 2017; 
Miles et al. 2015). In 2000, Notomi developed a new technique for the amplification of DNA called loop-mediated isothermal amplification (LAMP). LAMP is a highly sensitive and specific method for the detection of different organisms as compared with other molecular methods. Four or six primers are needed for completing amplification at the optimum temperature. The LAMP method can use deoxyribonucleic acid (DNA) or ribonucleic acid (RNA) as template for the amplification. LAMP assay has been reported in many previous studies for the detection and identification of many different plant pathogens (Dai et al. 2012; Duan et al. 2014; Niessen and Vogel 2010; Niu et al. 2012; Tomlinson et al. 2007, 2010; Yang et al. 2018; Zhang et al. 2018).

Cytochrome b (cyt-b) gene has been characterized for different plant pathogens, such as Puccinia recondita f. sp. tritici, $P$ graminis f. sp. tritici, A. solani, etc. (Grasso et al. 2006). The cyt-b gene contains slowly and rapidly evolving codon positions (Farias et al. 2001). Many previous studies have used the mitochondrial $c y t-b$ gene for the identification, exploration of evolution, classification, and phylogenetic analysis of many organisms (Aquadro and Greenberg 1983; Brown et al. 1979) such as Aspergillus spp. and Fusarium solani (He et al. 2011; Wang et al. 1998, 2000). The $c y t-b$ gene can be used as phylogenetic marker for analyzing the relationships among cichlid fish (Farias et al. 2001).

The objective of this work was to develop a LAMP assay, based on the $c y t-b$ gene, for the detection and identification of Alternaria spp. This method gives us a more effective and reliable detection technique as compared with other in vitro traditional assessment methods. Moreover, the LAMP assay is useful for laboratories and field identification of pathogens in developing countries, as it is easier and cheaper than other methods.

\section{Materials and Methods}

Fungal strains and plant materials. The fungal strains used in this study (Table 1) were obtained from the cultures stored at Anhui

Table 1. List of fungal species used for testing the specificity in the LAMP assay

\begin{tabular}{|c|c|c|c|c|c|}
\hline Species & Isolates ID & Host & Location & Source ${ }^{\mathbf{a}}$ & LAMP \\
\hline Alternaria alternata (strain 1) & DSL-1 & Dangshan Suli & Dangshan, Suzhou, AnHui, China & AAAS & + \\
\hline A. alternata (strain 2) & XXPGL & Pingguoli & Xiaoxian, Suzhou, AnHui, China & AAAS & + \\
\hline A. alternata (strain 3) & XXHJL & Whangkeumbae & Xiaoxian, Suzhou, AnHui, China & AAAS & + \\
\hline A. alternata (strain 4) & XXSJL & Shuijingli & Xiaoxian, Suzhou, AnHui, China & AAAS & + \\
\hline A. alternata (strain 5) & XXZSL & Zaosu & Xiaoxian, Suzhou, AnHui, China & AAAS & + \\
\hline A. alternata (strain 6) & XXFSL & Housui & Xiaoxian, Suzhou, AnHui, China & AAAS & + \\
\hline A. alternata (strain 7) & XXGL & Gongli & Xiaoxian, Suzhou, AnHui, China & AAAS & + \\
\hline A. alternata (strain 8) & XXXL & Xuehuali & Xiaoxian, Suzhou, AnHui, China & AAAS & + \\
\hline A. alternata (strain 9) & XJXL & Korla pear & Kuerle, Xinjiang, China & AAAS & + \\
\hline A. alternata & CFCM-1 & Strawberry & Changfeng, Hefei, AnHui, China & AHIQ & + \\
\hline A. alternata & DSPG-1 & Apple & Dangshan, Suzhou, AnHui, China & AAAS & + \\
\hline A. alternata & $\mathrm{J}-\mathrm{Aa}$ & Orange & - & AHIQ & + \\
\hline A. alternata & NM-Aa & Lemon & - & AHIQ & + \\
\hline A. alternata & YC-Aa & Tobacco & - & AHIQ & + \\
\hline A. alternata & FQ-Aa & Tomato & $\overline{-}$ & AHIQ & + \\
\hline A. tenuissima & DSL-2 & Pear & Dangshan, Suzhou, AnHui, China & AAAS & + \\
\hline A. gaisen & 3.7807 & $\ldots$ & _ & CGMCC & + \\
\hline A. infectoria & 3.7808 & - & - & CGMCC & - \\
\hline A. arborescens & 3.15534 & - & - & CGMCC & + \\
\hline A. citri & 3.10272 & - & $\overline{-}$ & CGMCC & + \\
\hline A. mali & 3.7809 & - & - & CGMCC & + \\
\hline A. porri & 3.7810 & - & - & CGMCC & - \\
\hline A. solani & FQZY & - & Nanjing Agriculture University & CGMCC & - \\
\hline A. longipes & 3.17855 & - & _ & CGMCC & + \\
\hline Ascochyta eriobotryae & SXPP-1 & Loquat & Shexian, Huangshan, AnHui, China & AAAS & - \\
\hline Aspergillus niger & FDPT-1 & Grape & Feidong, Hefei, AnHui, China & AAAS & - \\
\hline Aspergillus flavus & SXGJ-1 & Orange & Shexian, Huangshan, AnHui, China & AAAS & - \\
\hline Botryosphaeria dothidea & DSL-4 & Pear & Dangshan, Suzhou, AnHui, China & AAAS & - \\
\hline Botrytis cinerea & FCT-1 & Peach & Fanchang, Wuhu, AnHui, China & AAAS & - \\
\hline Colletotrichum gloeosporioides & DSL-3 & Pear & Dangshan, Suzhou, AnHui, China & AAAS & - \\
\hline Coniella granati & HYSL-1 & Pomegranate & Huaiyuan, Bengbu, AnHui, China & AAAS & - \\
\hline Coniothyrium diplodiella & FDPT-2 & Grape & Feidong, Hefei, AnHui, China & AAAS & - \\
\hline Fusarium oxysporum & CFXG-1 & Watermelon & Changfeng, Hefei, AnHui, China & AAAS & - \\
\hline Glomerella acutata & WHYT-1 & Nectarine & Wuhu, AnHui, China & AAAS & - \\
\hline Glomerella cingulata & LSSL-1 & Pomegranate & Lieshan, Huainan, AnHui, China & AAAS & - \\
\hline Monilinia fructicola & HSYT-1 & Cherry & Huangshan, AnHui, China & AAAS & - \\
\hline Nigrospora sphaerica & HSMHT-1 & Kiwifruit & Huangshan, AnHui, China & AAAS & - \\
\hline Penicillium purpurogenum & DSL-5 & Pear & Dangshan, Suzhou, AnHui, China & AAAS & - \\
\hline Pestalotiopsis punicae & LSSL-2 & Pomegranate & Lieshan, Huainan, AnHui, China & AAAS & - \\
\hline Pestalotiopsis theae & SXPP-2 & Loquat & Shexian, Huangshan, AnHui, China & AAAS & - \\
\hline Pestalotiopsis clavispora & TXLM-1 & Blueberry & Tunxi, Huangshan, AnHui, China & AAAS & - \\
\hline Phomopsis fukushii & DSL-6 & Pear & Dangshan, Suzhou, AnHui, China & AAAS & - \\
\hline Phomopsis punicae & LSSL-3 & Pomegranate & Lieshan, Huainan, AnHui, China & AAAS & - \\
\hline Phomopsis amygdalina & WHT-2 & Peach & Wuhu, AnHui, China & AAAS & - \\
\hline Plasmopar aviticola & FDPT-2 & Grape & Feidong, Hefei, AnHui, China & AAAS & - \\
\hline Sclerotinia sclerotiorum & FDYT-1 & Cherry & Feidong, Hefei, AnHui, China & AAAS & - \\
\hline
\end{tabular}

a AAAS: Anhui Academy of Agricultural Sciences; AHIQ: Anhui Entry-Exit Inspection and Quarantine Bureau; CGMCC: China General Microbiological Culture Collection Center. + and - indicate the presence and absence of the expected 229-bp DNA fragment amplified by LAMP primers. __ means no information available from the source. 
Academy of Agricultural Sciences (AAAS), Anhui Entry-Exit Inspection and Quarantine Bureau (AHIQ), and China General Microbiological Culture Collection Center (CGMCC). The fungal strains preserved at AAAS were collected from different orchards and markets. These strains are monosporic isolates and are identified according to their morphological features and ITS gene sequence BLAST results. Fungal infected pears showing black spot disease were collected from the field situated in Anhui Province of China. The infected tissue samples were taken from under the husk of the infected pear fruit and placed on potato dextrose agar (PDA) dishes. The isolates were characterized by the length of colonies on PDA at $25^{\circ} \mathrm{C}$ in the dark for 1 week. Then, the cultures were stored at $4{ }^{\circ} \mathrm{C}$ (Ramjegathesh and Ebenzar 2012; Simmons 1967, 1981).

DNA extraction. The biomass of each fungal strain was frozen in liquid nitrogen for breaking the cells and immediately physically ground using a mortar and pestle. Genomic DNA (gDNA) of all the fungal pathogens was extracted using the Fungal DNA Mini Kit (Omega Bio-tek, China), according to the manufacturer's protocol. The quantity of gDNA for each sample was determined by using the Nanodrop (NanoVue Plus, GE Healthcare Life Sciences), and was found between 50 and $100 \mathrm{ng} / \mu \mathrm{l}$.

Primer design. A specific region of the A. alternata cyt-b gene (JQ437357) was selected based on basic local alignment search tool (BLAST) results from NCBI sequence database. The specific site, showing no similarity to genes from any other fungal genera (as per data available in May 2017), was located from 2312 to $2541 \mathrm{bp}$ (a 229-bp region) in the $c y t-b$ gene (Fig. 1A and B). Two pairs of LAMP primers for amplifying these $229 \mathrm{bp}$ from the $c y t-b$ gene were designed based on the specific region using the Primer explorer V4 software program (http://primerexplorer.jp/e/) (Eiken Chemical Co., Ltd., Tokyo, Japan). The software recommended three sets of primers; we chose the best set of four primers according to the results of Primer explorer V4 software program. The primers were synthesized by Invitrogen Trading Shanghai Co., Ltd. (Table 2). The sequence of LAMP primers used in this study is shown in Figure 1. F1c and F2 together formed the forward inner primers (FIP), while B1c and B2 together formed the backward inner primers (BIP) (Notomi et al. 2000). The outer primers F3 and B3 were designed to start the LAMP reaction.

LAMP reaction. To optimize the reagents, the LAMP reaction was prepared by mixing $2 \mu$ l of $10 \times$ isothermal amplification buffer (New England Biolabs), different concentrations of $\mathrm{MgCl}_{2}(25 \mathrm{mM}$, Sangon, China) ( $2 \mathrm{mM}, 3 \mathrm{mM}, 4 \mathrm{mM}, 5 \mathrm{mM}$, and $6 \mathrm{mM}), 2 \mu \mathrm{l}$ of dNTP Mix (10 mM, Sangon, China), $0.6 \mu l$ of FIP and BIP primers (40 $\mu \mathrm{mol}), 0.6 \mu \mathrm{l}$ of $\mathrm{F} 3$ and B3 primers $(10 \mu \mathrm{mol}), 1 \mu \mathrm{l}$ of DNA $(50 \mathrm{ng}), 1.2 \mu \mathrm{l}$ of betaine (5 M) (Sigma, U.S.A.), and $0.8 \mu \mathrm{l}$ of Bst 2.0 WarmStart DNA polymerase $(8.000 \mathrm{U} / \mathrm{ml})$ (New England Biolabs). Additionally, $\mathrm{ddH}_{2} \mathrm{O}$ was added to make the final volume $20 \mu$ l. SYBR Green I (Sangon Biotech, Shanghai) was not added to the reaction mixture, but $0.25 \mu$ l of SYBR Green I was added to each tube after amplification. Reaction tubes were placed in a thermal cycler (BIO-RAD, Singapore). After amplification, LAMP reactions were examined based on the change in color of SYBR Green I, and gel electrophoresis ( $2 \%$ agarose gel for $50 \mathrm{~min}$ at $80 \mathrm{~V}$ ). Each

Table 2. Sequence information of LAMP primers used for amplification of the target sequence in $c y t-b$ gene

\begin{tabular}{|c|c|c|}
\hline Primer name & Type & Sequence $\mathbf{5}^{\prime} \rightarrow \mathbf{3}^{\prime}$ \\
\hline F3 & Forward outer & GGCTCCTTTGAATGGTAAC \\
\hline B3 & Backward outer & TGTCTTCAACCAAGCATCA \\
\hline FIP (F1c-F2) & $\begin{array}{l}\text { Forward inner } \\
\text { primer }\end{array}$ & $\begin{array}{l}\text { CGCTGCAAGTAATCTATAAATCGG } \\
\text { ATTCAATAGGCAAATGGGGA }\end{array}$ \\
\hline BIP (B1c-B2) & $\begin{array}{l}\text { Backward inner } \\
\text { primer }\end{array}$ & $\begin{array}{l}\text { AATGGATCAAGAACGTTCAACG } \\
\text { AATTGGTTGTGGGGTACTC }\end{array}$ \\
\hline
\end{tabular}

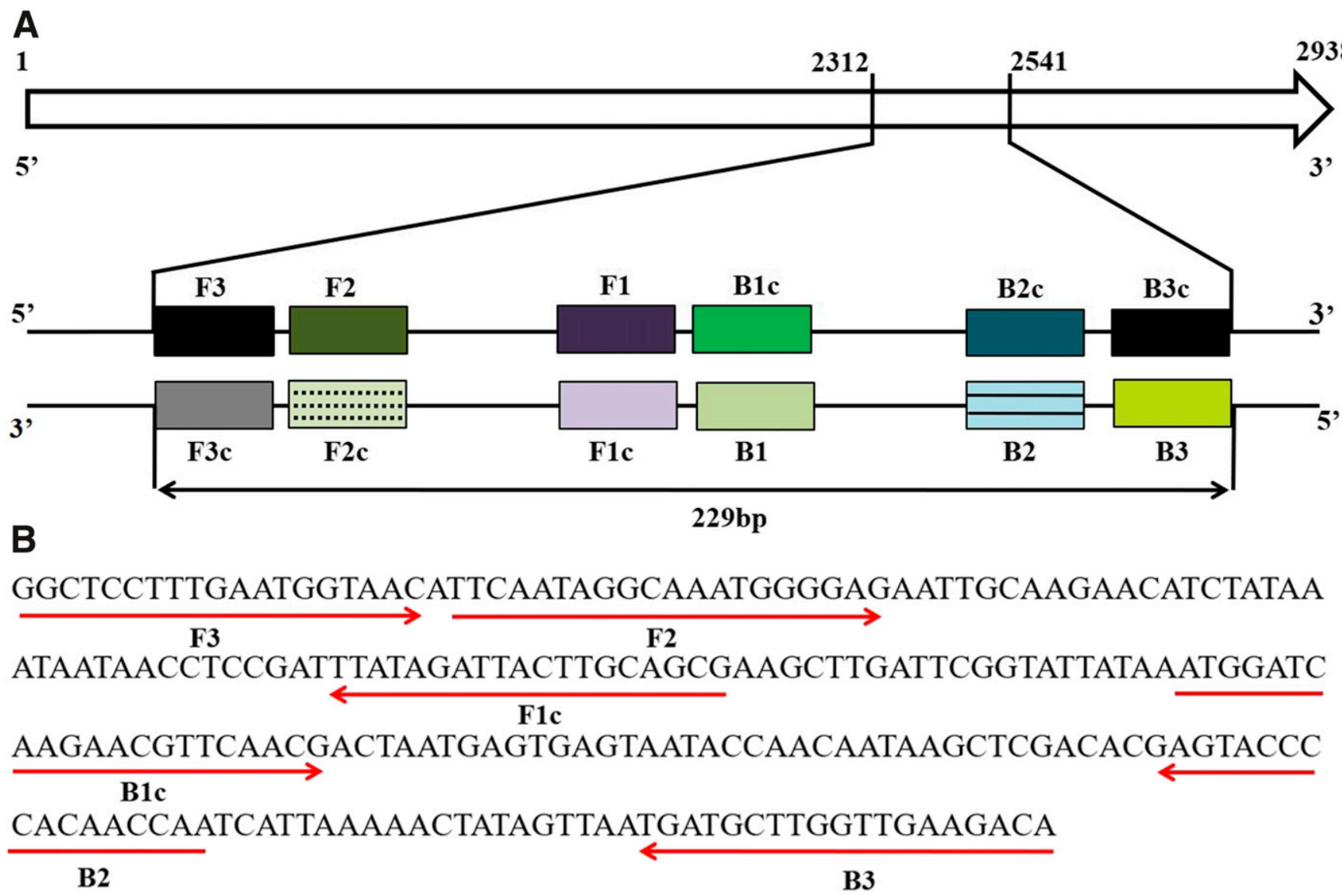

Fig. 1. Design of LAMP primers for the detection of a specific region in the cyt-b gene (JQ437357) in the Alternaria alternata genome. A, Schematic illustration of the LAMP primers used in this study. F1C and B1C are complementary to F1 and B1, respectively. B, Arrows show the locations of the LAMP primers. 
treatment was replicated three times and the experiment was repeated twice.

Optimization of LAMP reaction. Different concentrations of $\mathrm{MgCl}_{2}(25 \mathrm{mM}$ ), i.e., $2 \mathrm{mM}, 3 \mathrm{mM}, 4 \mathrm{mM}, 5 \mathrm{mM}$, and $6 \mathrm{mM}$, were used to determine the optimal LAMP reaction. Further, the mixture tubes were incubated at $65^{\circ} \mathrm{C}$ for $30 \mathrm{~min}, 45 \mathrm{~min}, 60 \mathrm{~min}, 75 \mathrm{~min}$, and $90 \mathrm{~min}$ to determine the optimal reaction time. Each treatment was replicated three times, and the experiment was repeated twice.

Specificity test of LAMP reaction. To study the specificity of LAMP, 46 different fungi were used in the study including 9 A. alternata strains isolated from different pear cultivars, 6 strains of A. alternata from different plant hosts, 9 strains of other Alternaria spp., and 22 other different fungal species belonging to other genera (Table 1). LAMP reaction conditions were based on optimization of experiments as mentioned above. The assay was evaluated based on the change in the color of SYBR Green I in amplification tubes. The experiment was repeated twice.

Sensitivity test of LAMP and PCR assays. To compare the sensitivity of PCR and LAMP, different concentrations of gDNA of $A$. alternata ranging from $10 \mu \mathrm{g}$ to $100 \mathrm{fg} / \mu \mathrm{l}$ were used. For PCR, F3 and B3 primers were used to amplify the same specific region (229 bp) of $c y t-b$ gene. PCR conditions included initial denaturation at $95^{\circ} \mathrm{C}$ for $3 \mathrm{~min} ; 35$ cycles of $95^{\circ} \mathrm{C}$ for $30 \mathrm{~s}, 60^{\circ} \mathrm{C}$ for $30 \mathrm{~s}$, and $72^{\circ} \mathrm{C}$ for $30 \mathrm{~s}$, and a final extension at $72^{\circ} \mathrm{C}$ for $10 \mathrm{~min}$. The total volume of the PCR was $25 \mu \mathrm{l}$, containing $9.5 \mu \mathrm{l}$ of $\mathrm{ddH}_{2} \mathrm{O}, 1 \mu \mathrm{l}$ of genomic DNA of A. alternata, $1 \mu \mathrm{l}$ of each primer (F3 and B3) (10 mM), and $12.5 \mu \mathrm{l}$ of $2 \times$ Taq Master Mix (Novoprotein). After the amplification, PCR products were examined by running on a $1 \%$ agarose gel for $30 \mathrm{~min}$ at $120 \mathrm{~V}$. The DNA ladder DL2000 was used for size references. For LAMP, the reaction conditions were based on the optimization experiments. The PCR and LAMP experiments were repeated twice.

Detection of black spot pathogen in pear samples. Twelve samples of healthy and eight samples of infected pear fruits were collected from the different fields of Anhui Province. About $10 \mathrm{~g}$ of plant tissue from each sample was used for the DNA extraction. The DNA was extracted using the Plant DNA Mini Kit (Omega Bio-tek, China) according to the manufacturer's protocol and used as a template for LAMP. The DNA of A. alternata and the distilled water were used as positive and negative control, respectively. The amplification was analyzed using SYBR Green I. The experiment was repeated twice.

\section{Results}

Designing of LAMP primers and assay. The Primer explorer V4 software program was used for designing two pairs of LAMP primers using $c y t-b$ gene sequence. In the conventional PCR, the F3 and B3 primers (forward and backward LAMP primers) were used for better DNA detection on $1.0 \%$ agarose gel electrophoresis (Fig. 1). In LAMP tubes, yellowish green color with SYBR Green I was indicative of a positive reaction in comparison with the negative control (Figs. 2, 3, and 4). The results confirmed that LAMP could be used for detection and identification of Alternaria spp.

Optimized LAMP reaction. LAMP reaction was prepared using A. alternata gDNA as a template to determine the optimal reaction conditions for the amplification. Results showed that the best detection time of well-formed bands was $60 \mathrm{~min}$, where the color of LAMP reaction changed to yellowish green. It was indicative of a positive reaction (Fig. 2A and B). In addition, the best concentration of $\mathrm{MgCl}_{2}(25 \mathrm{mM})$ was $3.2 \mu \mathrm{l}(4 \mathrm{mM})$ in the final LAMP reaction (Fig. 2C).

Sensitivity of LAMP and PCR assays. To investigate the sensitivity of LAMP assay, different concentrations of gDNA of A. alternata ranging from $10 \mu \mathrm{g}$ to $100 \mathrm{fg} / \mu \mathrm{l}$ in a ninefold serial dilution of DNA, were used in the study. The DNA amplification was observed in all concentrations from $10 \mu \mathrm{g}$ to $1 \mathrm{pg}$ but not in lower concentrations. The negative control showed no amplification under the same conditions (Fig. 3A). In the PCR assay, positive amplification reactions were observed at concentrations from 10 to $1 \mu \mathrm{g} / \mu \mathrm{l}$ (Fig. 3B). The above results showed that the LAMP assay was more sensitive than PCR assay.
Specificity of LAMP assay. Using 46 genomic DNAs of different fungal species, the color of SYBR Green I in the tubes containing gDNA of A. alternata, all six pathotypes and nine strains of Alternaria spp. changed to yellowish green except in A. porri, A. solani, and A. infectoria tubes after $1 \mathrm{~h}$ of reaction time at $65^{\circ} \mathrm{C}$. These results are indicative of positive reactions. The other 22 fungal genera and the negative control showed an orange color, suggesting no DNA amplification (Figs. 4 and 5). All results are shown in Table 1.

Detection of black spot pathogens in pear using LAMP. The LAMP assay was used for detecting Alternaria pathogenic fungi in pear tissues. The results showed that the LAMP assay succeeded for the detection of Alternaria spp. in the infected pear tissues among healthy ones. These results indicate that this specific region of the $A$. alternata $c y t$ - $b$ gene (JQ437357) can be used for the detection and identification of black spot pathogens on pear (Fig. 6).

\section{Discussion}

Alternaria species are the most commonly found fungi and can be detected in the soil and organic matter around the world. At least 268

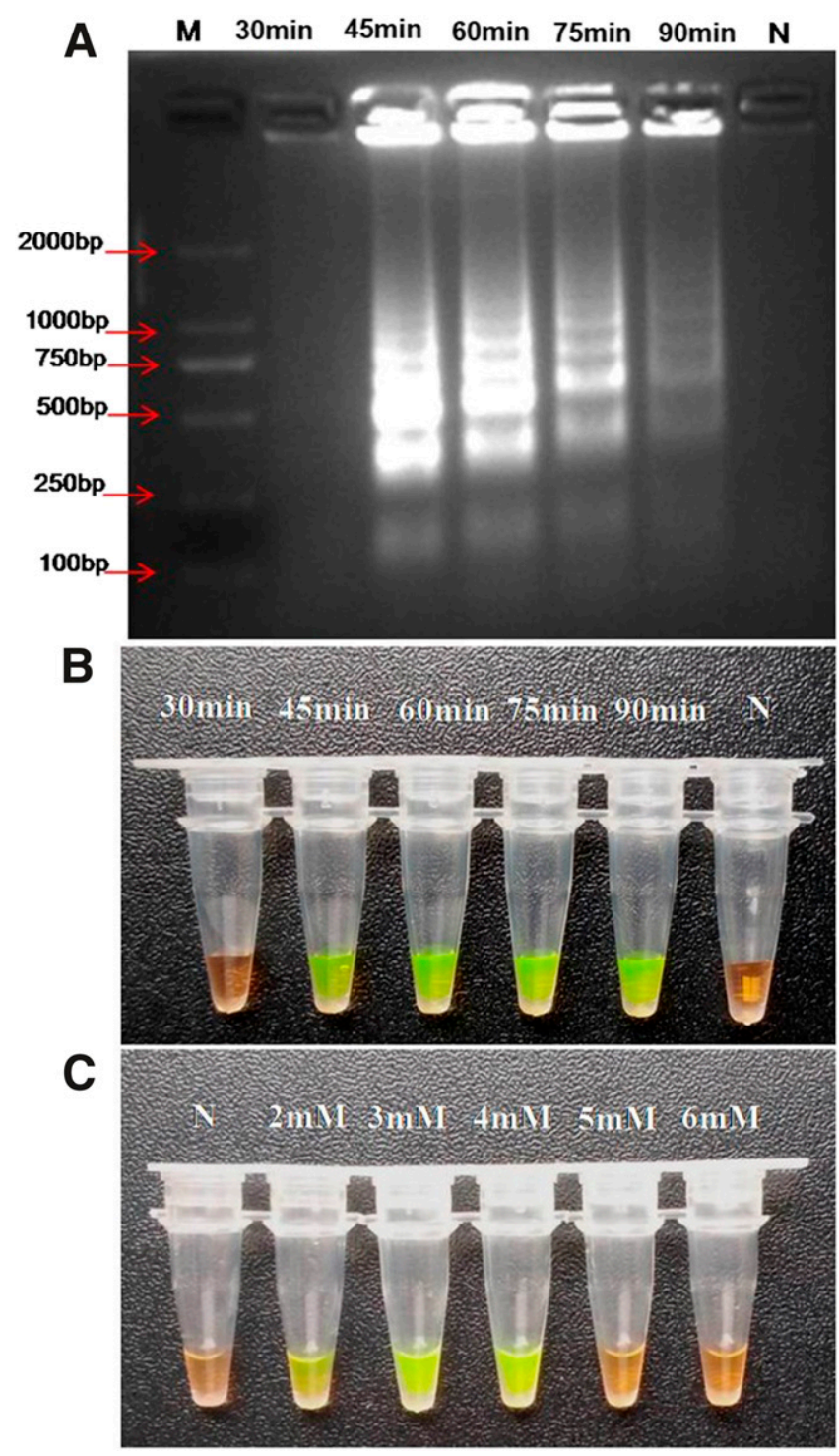

Fig. 2. Optimization of LAMP reaction for the detection of Alternaria alternata. Tubes and Lanes (A, B) are $30 \mathrm{~min}, 45 \mathrm{~min}, 60 \mathrm{~min}, 75 \mathrm{~min}$, and $90 \mathrm{~min}$, respectively. $\mathrm{N}$ is negative control (no DNA). A, $2 \%$ agarose gel showing products from the LAMP reaction. B, Visualization by SYBR Green I with different timings. C, Visualization by SYBR Green I with different concentrations of $\mathrm{MgCl}_{2}$. $\mathrm{N}$ is negative control (no DNA), Tubes 2-6 contain different $\mathrm{MgCl}_{2}$ concentrations including $2 \mathrm{mM}, 3 \mathrm{mM}$, $4 \mathrm{mM}, 5 \mathrm{mM}$, and $6 \mathrm{mM}$, respectively. The yellowish green color indicates a positive reaction, which can be easily distinguished from the reddish orange color indicating no reaction in the negative control under normal light. 
metabolites are produced by Alternaria species. Some metabolites from Alternaria fungi have a toxic effect on other organisms (Lou et al. 2013). A. alternata causes symptoms in leaves and fruits by producing phytotoxins (AK toxins I and II) (Kodama et al.1990; Maekawa et al. 1984; Tsuge et al. 2013). The fungal infection decreases the quality and quantity of pear fruit and has been continuously reported from countries such as China, Japan, and the United States (Roberts 2005, 2007; Sanada et al. 1988). Diagnosis of plant disease in the early fungal infection stage is one of the most challenging jobs for scientists and farmers. Morphological identification is now an ineffective method because microbiologic culture-based identification needs more time and space and is usually unreliable. Therefore, an effective, rapid, and reliable method for detecting different plant pathogens is needed. The LAMP assay achieves all these requirements and can successfully be used for the detection of many different plant pathogens (Almasi et al. 2013; Dai et al. 2012; Denschlag et al. 2012; Parida et al. 2005; Tomlinson et al. 2007, 2010; Vaagt et al. 2013), as well as animal pathogens (Iwamoto et al. 2003; Saetiew et al. 2011).

In this study, two pairs of primers (F3/B3 and FIP/BIP) were used to target a specific region of $c y t-b$ gene (JQ437357) of $A$. alternata fungus for the detection and identification of Alternaria spp. (Table 2). The specific region in the $c y t-b$ gene ranged from 2312 to 2541 bp (229-bp region) (Fig. 1) showed no homology with any other genera in BLAST result of NCBI database.

The optimal temperature, time duration, DNA quality, and $\mathrm{Mg}^{2+}$ ion concentrations affect the successful amplification reaction in LAMP method (Goto et al. 2009). We investigated the effect of $\mathrm{MgCl}_{2}$ concentration in the LAMP reaction. The results showed that the best concentration was $4 \mathrm{mM}$ of $\mathrm{MgCl}_{2}$ in LAMP reaction. In addition, we found that the optimized reaction conditions for successful amplification of DNA were $65^{\circ} \mathrm{C}$ and $60 \mathrm{~min}$. Many different dyes have been used previously to detect successful amplification of

A

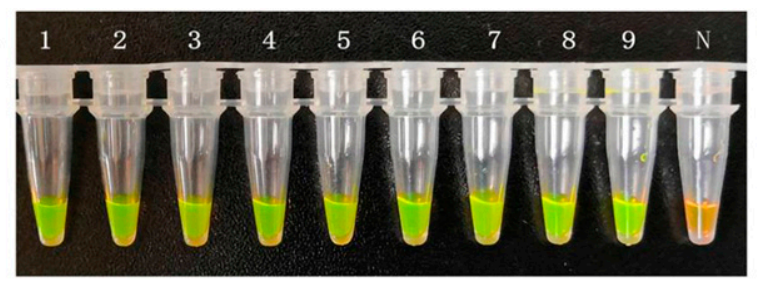

B
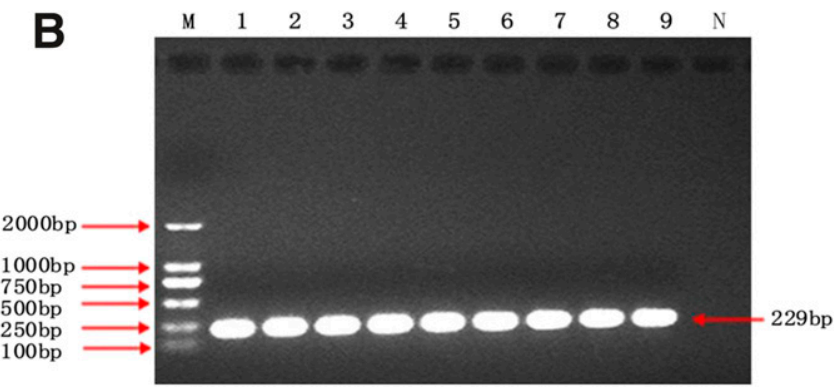

Fig. 4. The PCR and LAMP assay for Alternaria alternata detection in different infected pear samples. A, Tubes and B, Lanes 1-9 are from different cultivars: Pingguoli, Whangkeumbae, Shuijingli, Zaosu, Housui, Dangshan Suli, Xuehuali, Korla pear, Gongli, respectively. Tube and Lane $\mathrm{N}$ is the negative control (no DNA).

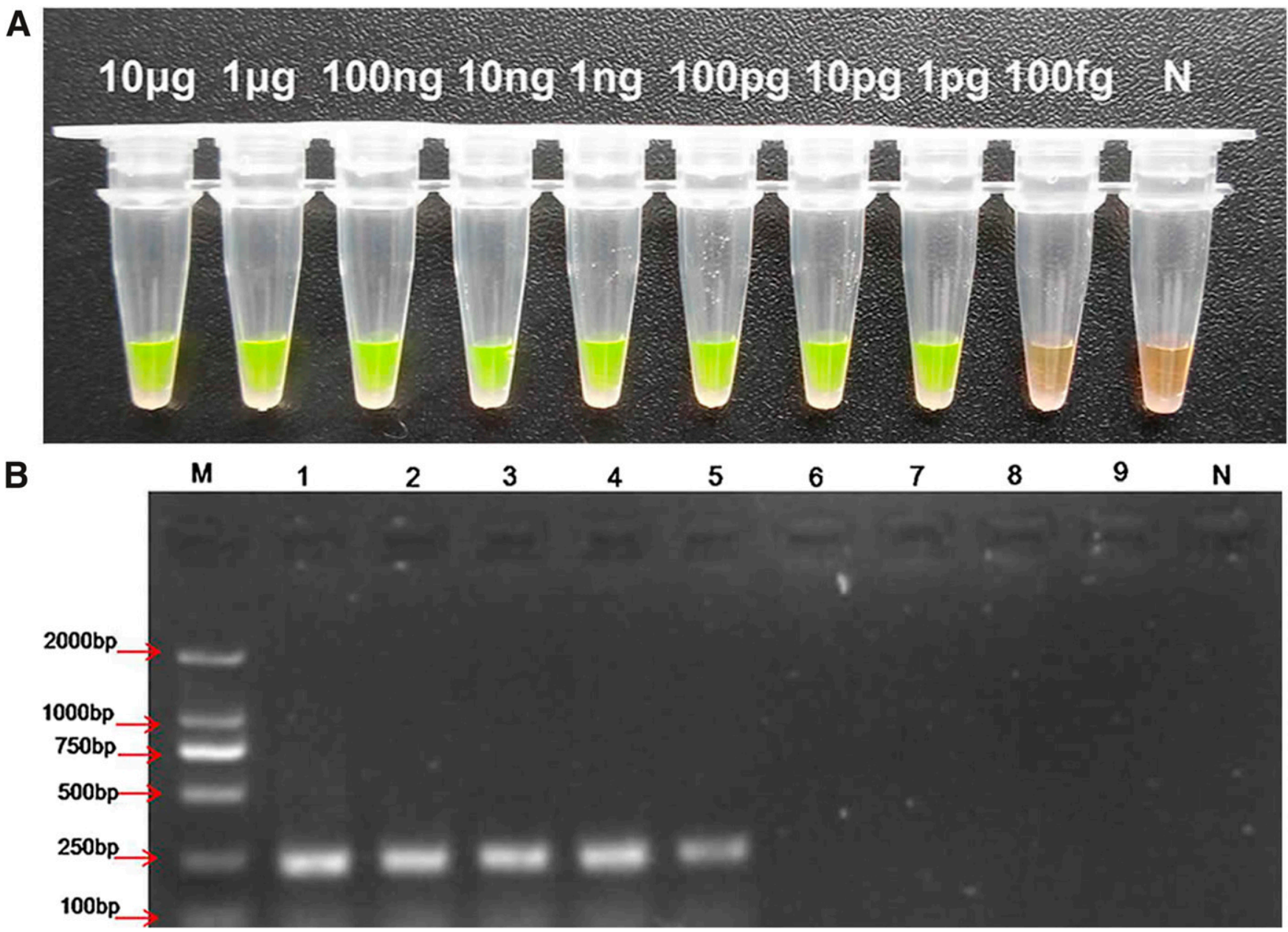

Fig. 3. Sensitivity of LAMP and PCR test for the detection of Alternaria alternata using different quantities of gDNA. A: Sensitivity of the LAMP test. Tubes 1-9, template DNA concentrations (10 $\mu \mathrm{g}, 1 \mu \mathrm{g}, 100 \mathrm{ng}, 10 \mathrm{ng}, 1 \mathrm{ng}, 100 \mathrm{pg}, 10 \mathrm{pg}, 1 \mathrm{pg}$, and $100 \mathrm{fg}$, respectively); N, negative control (no DNA). B: Sensitivity of the PCR test. M indicates the DL 2,000-bp DNA size marker; lanes 1-9 are template DNA concentrations ( $10 \mu \mathrm{g}, 1 \mu \mathrm{g}, 100 \mathrm{ng}, 10 \mathrm{ng}, 1 \mathrm{ng}, 100 \mathrm{pg}, 10 \mathrm{pg}, 1 \mathrm{pg}$, and $100 \mathrm{fg}$, respectively); and lane N is negative control (no DNA). 
DNA, such as hydroxynaphthol blue (HNB), SYBR Green I, magnesium pyrophosphate, ethidium bromide, and Genefinder. In this study, LAMP reaction tube was examined via SYBR Green I, which allowed the detection of differences between positive and negative reactions using the naked eye (Figs. 2, 3, 4, and 5). This is a simple method that visually differentiates between positive and negative reactions without demand for any special equipment.

Previous studies reported that the sensitivity of the LAMP reaction is generally higher than that of conventional PCR (Goto et al. 2009; Mori et al. 2004; Niessen and Vogel 2010; Zhao et al. 2015). This study reports the sensitivity limit of LAMP primers for the detection of Alternaria spp. using gDNA of A. alternata. The amplification limit of the LAMP assay was approximately $1 \mathrm{pg}$ of A. alternata target DNA, compared with $1 \mathrm{ng}$ of A. alternata target DNA through conventional PCR. The results demonstrate the high sensitivity of LAMP primers.

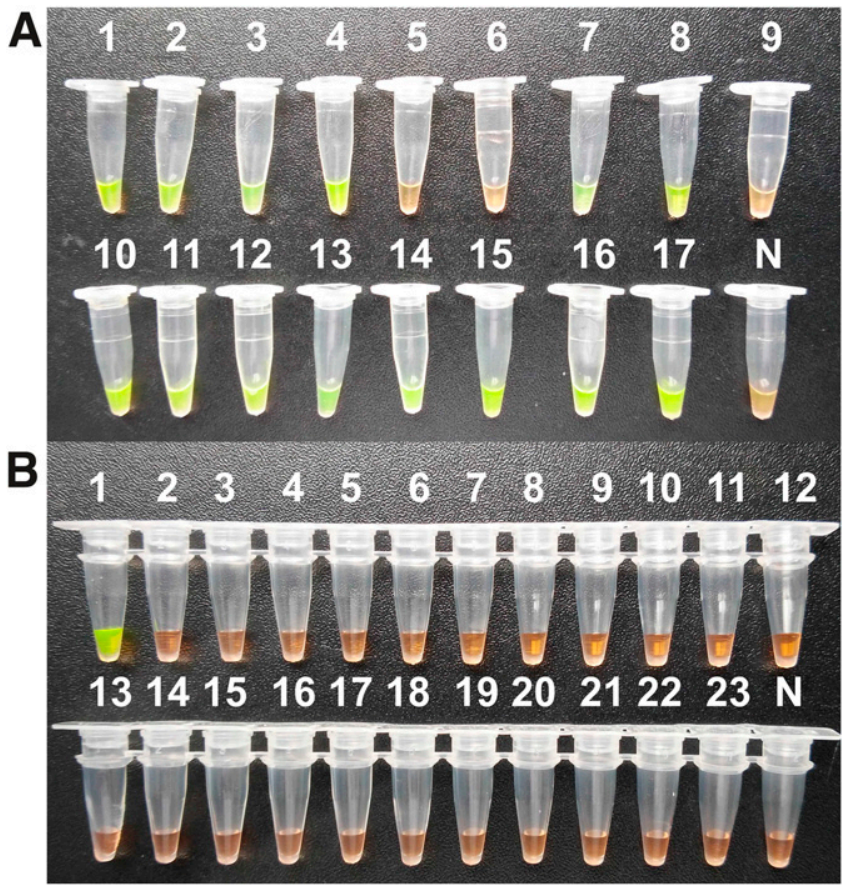

Fig. 5. Specificity of the LAMP assay visualized by SYBR Green I color change. A: Alternaria alternata from different host and other Alternaria species. Tubes 1-10 are A. alternata, A. tenuissima, A. gaisen, A. arborescens, A. infectoria, A. solani, A. mali, $A$. longipes, $A$. porri, and $A$. citri; Tubes $11-17$ are $A$. alternata pathotypes (pear pathotype, apple pathotype, orange pathotype, strawberry pathotype, lemon pathotype, tomato pathotype, and tobacco pathotype, respectively). B: Lane 1 is $A$. alternata, showing amplification; Lanes 2-23 are the other tested fungi, showing no amplifications. Lane $\mathrm{N}$ is the negative control (no DNA).

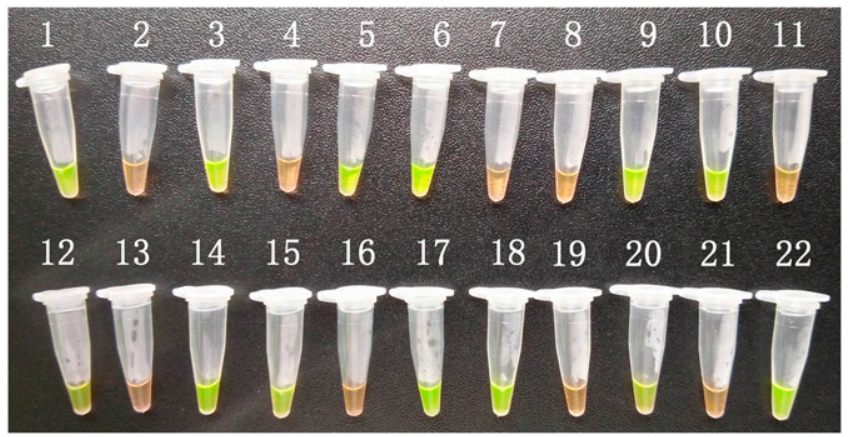

Fig. 6. Evaluation of the LAMP assays using infected and healthy pear samples with visualization of color change by SYBR Green I in amplification tubes. Tube 1 is the positive control (DNA). Tube 2 is the negative control (no DNA). Tubes 3, 5, 6, 9, 10, 12, 14, 15, 17, 18, 20, 22 are infected samples. Tubes 4, 7, 8, 11, 13, 16, 19, 21 are healthy samples.
In addition, we studied the specificity of LAMP primers for the identification of the black spot pathogen among other different fungal species. The results showed that LAMP primers could detect $A$. alternata species-group and Alternaria spp. among different genera, but LAMP primers can't detect $A$. porri, A. solani, and A. infectoria (Table 1; Fig. 5). The results also show that there is no crossreactivity with other fungi from different genera or negative control. Our test is easier and faster as compared with the conventional PCR method for the detection and identification of Alternaria spp. This result also suggests that $c y t$ - $b$ gene might be different with several Alternaria species, and the results are compatible with other reports in which $c y t-b$ gene was used to identify many other fungi as Aspergillus spp. and $F$. solani (Aquadro and Greenberg 1983; Brown et al. 1979; He et al. 2011; Wang et al. 1998, 2000).

Moreover, the LAMP assay proved to be a rapid and easy method for the detection of black spot pathogens in infected tissues of pear (Fig. 6), as all the three pathogens causing pear black spot reported from China belong to the Alternaria genus. This indicates that the LAMP method is efficient for the detection of pathogen from infected tissues, which confirms some previous studies conducted on the detection of different plant pathogens (Almasi et al. 2013; Dai et al. 2012; Denschlag et al. 2012; Parida et al. 2005; Tomlinson et al. 2007, 2010; Vaagt et al. 2013; Yang et al. 2018).

Finally, there are many advantages of the LAMP assay which make it the most preferred method for the detection of plant pathogens; it is simple, fast, cost effective, can be directly judged using naked eye, and doesn't need any special processing or electrophoresis device. Moreover, either DNA or RNA can be used as a template for amplification in LAMP assay. However, LAMP assay has some limitations and defects, as it is easily contaminated, needs a source of light, and requires some skill for assessing the results (Chowdry et al. 2014; Mitsunaga et al. 2013; Mori et al. 2001).

Conclusively, the LAMP assay can be useful for the rapid detection of Alternaria spp. including A. alternata on infected pears. The LAMP technique excludes the need for sophisticated equipment such as PCR machines, gel electrophoresis, and gel-imaging systems for the detection of Alternaria spp. in the laboratory. The LAMP method is quite sensitive for A. alternata pathotypes detection and could be a useful tool for pathologists in designing integrated control programs for black spot fungal disease and many other diseases caused by Alternaria species.

\section{Acknowledgments}

We thank Dr. Farman Ali and Dr. Mohamed Yasser Abdalla for their excellent editorial suggestions.

\section{Literature Cited}

Al-Nadabi, H. H., Maharachchikumbura, S. S. N., Agrama, H., Al-Azri, M., Nashehi, A., and Al-Sadi, A. M. 2018. Molecular characterization and pathogenicity of Alternaria species on wheat and date palms in Oman. Eur. J. Plant Pathol. 152:577-588.

Almasi, M. A., Ojaghkandi, M. A., Hemmatabadi, A., Hamidi, F., and Aghaei, S 2013. Development of colorimetric loop-mediated isothermal amplification assay for rapid detection of the tomato yellow leaf curl virus. J. Plant Pathol. Microbiol. 4:1-6.

Aquadro, C. F., and Greenberg, B. D. 1983. Human mitochondrial DNA variation and evolution: Analysis of nucleotide sequences from seven individuals. Genetics 103:287-312.

Bao, L., Chen, K., Zhang, D., Li, X., and Teng, Y. 2008. An assessment of genetic variability and relationships within Asian pears based on AFLP (amplified fragment length polymorphism) markers. Sci. Hortic. (Amsterdam) 116: 374-380.

Bassil, N., and Postman, J. D. 2010. Identification of European and Asian pears using EST-SSRs from Pyrus. Genet. Resour. Crop Evol. 57:357-370.

Brown, W. M., George, M., Jr., and Wilson, A. C. 1979. Rapid evolution of animal mitochondrial DNA. Proc. Natl. Acad. Sci. 76:1967-1971.

Chowdry, V. K., Luo, Y., Widén, F., Qiu, H. J., Shan, H., Belák, S., and Liu, L. 2014. Development of a loop-mediated isothermal amplification assay combined with a lateral flow dipstick for rapid and simple detection of classical swine fever virus in the field. J. Virol. Methods 197:14-18.

Dai, T. T., Lu, C. C., Lu, J., Dong, A. M., Ye, W. W., Wang, Y. C., and Zheng, X. B. 2012. Development of a loop-mediated isothermal amplification assay for detection of Phytophthora sojae. FEMS Microbiol. Lett. 334: 27-34. 
Dang, H. X., Pryor, B., Peever, T., and Lawrence, C. B. 2015. The Alternaria genomes database: A comprehensive resource for a fungal genus comprised of saprophytes, plant pathogens, and allergenic species. BMC Genomics 16: 239

Denschlag, C., Vogel, R. F., and Niessen, L. 2012. Hyd5 gene-based detection of the major gushing-inducing Fusarium spp. In a loop-mediated isothermal amplification (LAMP) assay. Int. J. Food Microbiol. 156:189-196.

Duan, Y., Ge, C., Zhang, X., Wang, J., and Zhou, M. 2014. A rapid detection method for the plant pathogen Sclerotinia sclerotiorum based on loopmediated isothermal amplification (LAMP). Australas. Plant Pathol. 43:61-66.

Farias, I. P., Orti, G., Sampaio, I., Schneider, H., and Meyer, A. 2001. The cytochrome $b$ gene as a phylogenetic marker: The limits of resolution for analyzing relationships among cichlid fishes. J. Mol. Evol. 53:89-103.

Gannibal, P. B. 2015. Distribution of Alternaria species among sections 2. Section Alternaria. Mycotaxon 130:941-949.

Goto, M., Honda, E., Ogura, A., Nomoto, A., and Hanaki, K. 2009. Colorimetric detection of Loop-mediated isothermal amplification reaction by using hydroxynaphthol blue. Biotechniques 46:167-172.

Grasso, V., Palermo, S., Sierotzki, H., Garibaldi, A., and Gisi, U. 2006. Cytochrome $b$ gene structure and consequences for resistance to Qo inhibitor fungicides in plant pathogens. Pest Manag. Sci. 62:465-472.

He, D., Hao, J., Bo, Z., Yang, Y., Song, W., Zhang, Y., Yokoyama, K., and Wang, L. 2011. Pathogenic spectrum of fungal keratitis and specific identification of Fusarium solani. Immunol. Microbiol. 52:2804-2808.

He, F., Li, B., Ai, G., Kange, A. M., Zhao, Y., Zhang, X., Jia, Y., Dou, D., Liu, F., and Cao, H. 2018. Transcriptomics analysis of the Chinese pear pathotype of Alternaria alternata gives insights into novel mechanisms of HSAF antifungal activities. Int. J. Mol. Sci. 19:1841.

Ito, K., Tanaka, T., Hatta, P., Yammamoto, M., Akimitsu, K., and Tsuge, T. 2004. Dissection of the host range of the fungal plant pathogen Alternaria alternata by modification of secondary metabolism. Mol. Micro. 52:399-411.

Iwamoto, T., Sonobe, T., and Hayashi, K. 2003. Loop-mediated isothermal amplification for direct detection of Mycobacterium tuberculosis complex, M. avium, and $M$. intracellulare in sputum samples. J. Clin. Microbiol. 41: 2616-2622.

Kodama, M., Suzuki, T., Otani, H., Kohmoto, K., and Nishimura, S. 1990. Purification and bioassay of host selective AT-toxin from Alternaria alternata causing brown spot of tobacco. Ann. Phytopathol. Soc. Jpn. 56:628-636.

Lau, H. Y., and Botella, J. R. 2017. Advanced DNA-based point-of-care diagnostic methods for plant diseases detection. Front. Plant Sci. 8:2016.

Logrieco, A., Bottalico, A., Mulé, M., Moretti, A., and Perrone, G. 2003. Epidemiology of toxigenic fungi and their associated mycotoxins for some Mediterranean crops. Eur. J. Plant Pathol. 109:645-667.

Lou, J., Fu, L., Peng, Y., and Zhou, L. 2013. Metabolites from Alternaria fungi and their bioactivities. Molecules 18:5891-5935.

Maekawa, N., Yamamoto, M., Nishimura, S., Kohmoto, K., Kuwada, K., and Watanabe, Y. 1984. Studies on host-specific AF-toxins produced by Alternaria alternata strawberry pathotype causing Alternaria black spot of strawberry. Production of host-specific toxins and their biological activities. Ann. Phytopathol. Soc. Jpn. 50:600-609.

Meena, M., Gupta, S. K., Swapnil, P., Zehra, A., Dubey, M. K., and Upadhyay, R. S. 2017. Alternaria toxins: Potential virulence factors and genes related to pathogenesis. Front. Microbiol. 8:1451.

Miles, T. D., Martin, F. N., and Coffey, M. D. 2015. Development of rapid isothermal amplification assays for detection of Phytophthora spp. in plant tissue. Phytopathology 105:265-278.

Mitsunaga, S., Shimizu, S., Okudaira, Y., Oka, A., Tanaka, M., Kimura, M., Kulski, J. K., Inoue, I., and Inoko, H. 2013. Improved loop-mediated isothermal amplification for HLA-DRB1 genotyping using RecA and a restriction enzyme for enhanced amplification specificity. Immunogenetics 65:405-415.

Mori, Y., Kitao, M., Tomita, N., and Notomi, T. 2004. Real-time turbidimetry of LAMP reaction for quantifying template DNA. J. Biochem. Biophys. Methods 59:145-157.

Mori, Y., Nagamine, K., Tomita, N., and Notomi, T. 2001. Detection of loopmediated isothermal amplification reaction by turbidity derived from magnesium pyrophosphate formation. Biochem. Biophys. Res. Commun. 289:150-154

Niessen, L., and Vogel, R. F. 2010. Detection of Fusarium graminearum DNA using a loop-mediated isothermal amplification (LAMP) assay. Int. J. Food Microbiol. 140:183-191.

Niu, J. H., Jian, H., Guo, Q. H., Chen, C. L., Wang, X. Y., Liu, Q., and Guo, Y. D. 2012. Evaluation of loop-mediated isothermal amplification (LAMP) assays based on 5S rDNA-IGS2 regions for detecting Meloidogyne enterolobii. Plant Pathol 61:809-819.
Notomi, T., Okayama, H., Masubuchi, H., Yonekawa, T., Watanabe, K., Amino, N., and Hase, T. 2000. Loop-mediated isothermal amplification of DNA. Nucleic Acids Res. 28:E63.

Parida, M., Horioke, K., Ishida, H., Dash, P. K., Saxena, P., Jana, A. M., Islam, M. A., Inoue, S., Hosaka, N., and Morita, K. 2005. Rapid detection and differentiation of dengue virus serotypes by a real-time reverse transcriptionloop-mediated isothermal amplification assay. J. Clin. Microbiol. 43:2895-2903.

Peever, T. L., Su, G., Carpenter-Boggs, L., and Timmer, L. W. 2004. Molecular systematic of citrus-associated Alternaria species. Mycologia 96:119-134.

Ramjegathesh, R., and Ebenzar, E. G. 2012. Morphological and physiological characters of Alternaria alternata causing leaf blight disease of onion. Inter J. Plant Pathol. 3:34-44.

Reis, R. F., Almeida, T. F., Stuchi, E. S., and Goes, A. 2007. Susceptibility of citrus species to Alternaria alternata, the causal agent of the Alternaria brown spot. Sci. Hortic. (Amsterdam) 113:336-342.

Roberts, R. G. 2005. Alternaria yaliinficiens sp. nov. on Ya Li pearfruit: From interception to identification. Plant Dis. 89:134-145.

Roberts, R. G. 2007. Two new species of Alternaria from pear fruit. Mycotaxon 100:159-167.

Saetiew, C., Limpaiboon, T., Jearanaikoon, P., Daduang, S., Pientong, C., Kerdsin, A., and Daduang, J. 2011. Rapid detection of the most common high-risk human papilloma viruses by loop-mediated isothermal amplification. J. Virol Methods 178:22-30.

Sanada, T., Nishida, T., and Ikeda, F. 1988. Resistant mutant to black spot disease of Japanese pear 'Nijisseiki' induced by gamma rays. J. Jpn. Soc. Hortic. Sci. 57:159-166.

Simmons, E. G. 1967. Typification of Alternaria, Stemphylium, and Ulocladium. Mycologia 59:67-92

Simmons, E. G. 1981. Alternaria themes and variations (1-6). Mycotaxon 13 $6-34$

Simmons, E. G. 2007. Alternaria: An Identification Manual. CBS Biodiversity Series 6:1-775.

Tanahashi, M., Nakano, T., Akamatsu, H., Kodama, M., Otani, H., and Osaki-Oka, K. 2016. Alternaria alternata apple pathotype (A. mali) causes black spot of European pear. Eur. J. Plant Pathol. 145:787-795.

Terakami, S., Kimura, T., Naishitani, C., Sawamura, Y., Saito, T., Hirabayashi, T., and Yamamoto, T. 2009. Genetic linkage map of the Japanese pear 'Housui' identifying three homozygous genomic regions. J. Jpn. Soc. Hortic. Sci. 78: 417-424.

Tomlinson, J. A., Barker, I., and Boonham, N. 2007. Faster, simpler, more-specific methods for improved molecular detection of Phytophthora ramorum in the field. Appl. Environ. Microbiol. 73:4040-4047.

Tomlinson, J. A., Dickinson, M. J., and Boonham, N. 2010. Detection of Botrytis cinerea by loop-mediated isothermal amplification. Lett. Appl. Microbiol. 51: 650-657.

Tsuge, T., Harimoto, Y., Akimitsu, K., Ohtani, K., Kodama, M., Akagi, Y., Equsa, M., Yamamoto, M., and Otani, H. 2013. Host-selective toxins produced by the plant pathogenic fungus Alternaria alternata. FEMS Microbiol. Rev. 37:44-66.

Vaagt, F., Haase, I., and Fischer, M. 2013. Loop-mediated isothermal amplification (LAMP)-based method for rapid mushroom species identification. J. Agric Food Chem. 61:1833-1840.

Wang, L., Yokoyama, K., Miyaji, M., and Nishimura, K. 1998. The identification and phylogenetic relationship of pathogenic species of Aspergillus based on the mitochondrial cytochrome b gene. Med. Mycol. 36:153-164.

Wang, L., Yokoyama, K., Miyaji, M., and Nishimura, K. 2000. Mitochondria cytochrome $\mathrm{b}$ gene analysis of Aspergillus fumigatus and related species. J. Clin. Microbiol. 38:1352-1358.

Wolko, Ł., Antkowiak, W., Lenartowicz, E., and Bocianowski, J. 2010. Genetic diversity of European pear cultivars (Pyrus communis L.) and wild pear (Pyrus pyraster (L.) Burgsd.) inferred from microsatellite markers analysis. Genet. Resour. Crop Evol. 57:801-806.

Yang, X., Al-Attala, M. N., Zhang, Y., Zhang, A. F., Zang, H. Y., Gu, C. Y., Gao, T. C., Chen, Y., Ali, F., Li, Y. F., Yao, J., and Zhu, J. G. 2018. Rapid detection of Ustilaginoidea virens from rice using loop-mediated isothermal amplification assay. Plant Dis. 102:1741-1747.

Zhang, H., Wang, Y., Zhang, C., Wang, X., Li, H., and Xu, H. 2011. Isolation, characterization and expression analysis of resistance gene candidates in pear (Pyrus spp.). Sci. Hortic. (Amsterdam) 127:282-289.

Zhang, J., Borth, W., Lin, B., Melzer, M., Shen, H., Pu, X., Sun, D., Nelson, S., and Hu, J. 2018. Multiplex detection of three banana viruses by reverse transcription loop-mediated isothermal amplification (RT-LAMP). Trop. Plant Pathol. 43: 543-551.

Zhao, W., Wang, T., and Qi, R. 2015. Ypt1 gene-based detection of Phytophthora sojae in a loop-mediated isothermal amplification assay. J. Plant Dis. Prot. 122 $66-73$ 